LIÑO 25. Revista Anual de Historia del Arte. 2019 (pags. 151-162)

\title{
José Gestoso y la historiografía artística de su tiempo (1852-1917)'
}

\author{
Carmen de Tena Ramírez \\ Universidad de Sevilla
}

\section{RESUMEN:}

La finalidad de este trabajo de investigación es dar a conocer la figura de José Gestoso y sus aportaciones a la historiografía artística española. Para ello nos hemos valido de un estudio sobre las características de la práctica historiográfica restauracionista y de un análisis de las investigaciones llevadas a cabo por este erudito, así como de algunos aspectos de su personalidad. Como conclusión destacamos el carácter precursor de las investigaciones de José Gestoso sobre el patrimonio histórico-artístico español y la aplicación del estudio y conocimiento del mismo para su tutela.

\section{PALABRAS CLAVE:}

historiografía artística, historia de la Historia del Arte, protección del patrimonio monumental, Escuela Superior de Diplomática, Restauración borbónica.

\section{ABSTRACT:}

The main purpose of this paper is to make known the figure of José Gestoso and his contributions to Spanish artistic historiography. In order to do so, we have used a study of the characteristics of the historiographic practice of his time and an analysis of the research carried out by this scholar, as well as some aspects of his personality. As a conclusion to this study, we highlight the pioneering nature of José Gestoso's research on Spanish monumental heritage and the application of the study and knowledge of it for its protection.

\section{KEYWORDS:}

Art Historiography, history of Art History, protection of monumental heritage, Escuela Superior de Diplomática, Bourbon restoration.

Este trabajo forma parte del proyecto La Historia del arte en España: desarrollo histórico y nuevas perspectivas, integrado en el convenio de investigación suscrito entre la Fundación de Cultura Andaluza y la Universidad de Sevilla 
El 26 de septiembre del año 2017 se cumplió el primer centenario de la muerte de José Gestoso y Pérez (Sevilla, 1852-1917), erudito, archivero, bibliófilo, diseñador y profesor en la Escuela de Artes e Industrias y de Bellas Artes de Sevilla. Se trata de una de las figuras clave del ambiente cultural español de finales del siglo XIX y principios del XX, especialmente conocido y reconocido por sus aportaciones a la historiografía artística española y la conservación de monumentos y obras de arte $^{2}$. El interés de José Gestoso por la investigación histórico-artística, sus habilidades intelectuales, su carácter laborioso y constante y sin duda, el apoyo y estímulo de importantes personajes de la élite cultural española e internacional, hicieron de él una figura esencial para el desarrollo de la Historia del Arte en España.

A pesar de la importancia de su prolífica obra historiográfica y de su participación en actividades culturales de diversa índole, hasta la citada efeméride la falta de estudios especializados sobre su trayectoria vital ha sido llamativa. Cierto es que ya habían sido estudiadas y analizadas algunas de sus obras o ciertas facetas de su actividad profesional ${ }^{3}$ pero al margen de estas

Así se reconoce en los primeros estudios publicados sobre este personaje: PLEGUEZUELO HERNÁNDEZ, Alfonso, "Presentación", en Historia de los barros vidriados sevillanos: desde sus orígenes hasta nuestros dias, Servicio de Publicaciones del Ayuntamiento de Sevilla, Sevilla, 1995, pp. VII-XXIII; FERNÁNDEZ GÓMEZ, Marcos, "Presentación", en Noticia histórico - descriptiva del antiguo pendón de la ciudad de Sevilla... Servicio de Publicaciones del Ayuntamiento de Sevilla, Sevilla, 1999, VII-XXIX; ALBARDONED0 FREIRE, Antonio, "Precursores del Laboratorio de Arte: D. José Gestoso y sus trabajos patrocinados por el Ayuntamiento de Sevilla", en Estudios de Historia del Arte: centenario del Laboratorio de Arte (1907-2007), Servicio de Publicaciones de la Universidad de Sevilla, Sevilla, 2009, vol. I, p. 45-62; RECIO MIR, Álvaro, "Alfonso XIII, José Gestoso y el Alcázar de Sevilla”, en Estudios de Historia del Arte, opus. cit., pp. 119-133.

Véase nota 1; a estos estudios debemos añadir CÓMEZ RAMOS, Pedro, Catálogo de los tomos de manuscritos (Papeles Varios) del fondo documental José Gestoso existente en la Biblioteca Capitular y Colombina de Sevilla. Memoria de licenciatura dirigida por Francisco Morales Padrón, Sevilla, 1975; PLEGUEZUELO HERNÁNDEZ, Alfonso, “José Gestoso y la recuperación de la cerámica sevillana (1855-1908)”, en Renacimientos: la cerámica española en tiempos de Ruiz de Luna, Universidad de Castilla y la Mancha, Cuenca, 2010, pp. 71-90; RECIO MIR, Álvaro, "El sepulcro neogótico del cardenal Cienfuegos en la catedral de Sevilla y la crítica de Gestoso a su concepto artístico", Laboratorio de Arte, 21, Sevilla, 2008-2009, pp. 219-239; RUIZ DE LACANAL RUIZ-MATEOS, María-Dolores, “José aportaciones, hasta hace pocos meses la figura de José Gestoso había carecido de un análisis profundo sobre su formación, su carrera como investigador de la historia y del arte y la proyección de la misma en la salvaguarda de patrimonio monumental, entre otras actuaciones.

Afortunadamente y con el fin de homenajear al personaje a los cien años de su muerte, se han emprendido distintos proyectos de investigación gracias a los cuales tenemos un conocimiento mucho más amplio de todas las actividades y facetas en las que sobresalió este polifacético personaje. Entre todas ellas destaca la biografía escrita por Nuria Casquete de Prado en la que a la par que una visión panorámica de la vida y obra de José Gestoso, nos ofrece información documental de gran interés extraída del archivo personal que este legó a la Biblioteca Capitular y Colombina de Sevilla ${ }^{4}$. Tal y como esta obra nos muestra, en José Gestoso confluyen dos circunstancias que hacen que su vida y obra resulten cuanto menos, laboriosas de estudiar y analizar: por un lado, la riqueza del ambiente sociocultural en el que vivió; por otro, la intensa actividad desarrollada durante casi toda su vida. Es por ello que su compleja personalidad merece una visión amplia y transversal ${ }^{5}$.

En esta ocasión presentamos un análisis sobre la obra historiográfica de José Gestoso, que hemos planteado como una contribución al conocimiento de la historia de la Historia del Arte en España. Nos alineamos con la opinión de la profesora Jesusa Vega y su recomendación de acometer la relectura contextualizada de la historiografía que produjeron los prime-

Gestoso y Pérez: teoría y praxis de la conservación", Ge-Conservación, 4, 2013, Madrid, pp. 59-70.

4 CASQUETE DE PRADO Y SAGRERA, Nuria, José Gestoso y Sevilla: biografía de una pasión, Ayuntamiento de Sevilla - ICAS, Sevilla, 2016; otros estudios parciales sobre el personaje publicados de la misma autora: "Dejando huella. José Gestoso, el Cabildo y la Catedral de Sevilla (1875-1917)", Anuario de Historia de la Iglesia andaluza, vol. 10, Sevilla, 2017, pp. 289-324; "El Fondo Gestoso de la Biblioteca Capitular y Colombina: historia y descripción”, Isidorianum, vol. 26, n 51-52, Sevilla, 2017, pp. 51-52; "José Gestoso y sus servicios en favor de la Biblioteca Colombina”, Archivo Hispalense, t. 100, $\mathrm{n}^{\circ}$ 303-305, Sevilla, 2017, pp. 13-44.

5 Los profesores de la Universidad de Sevilla Alfonso Pleguezuelo y Carmen de Tena organizaron un ciclo de conferencias a finales del año 2017, en el que reunieron a distintos especialistas con el fin de abordar todos los perfiles que formaron parte de la actividad pública de José Gestoso; las participaciones de este encuentro académico serán publicadas próximamente. 


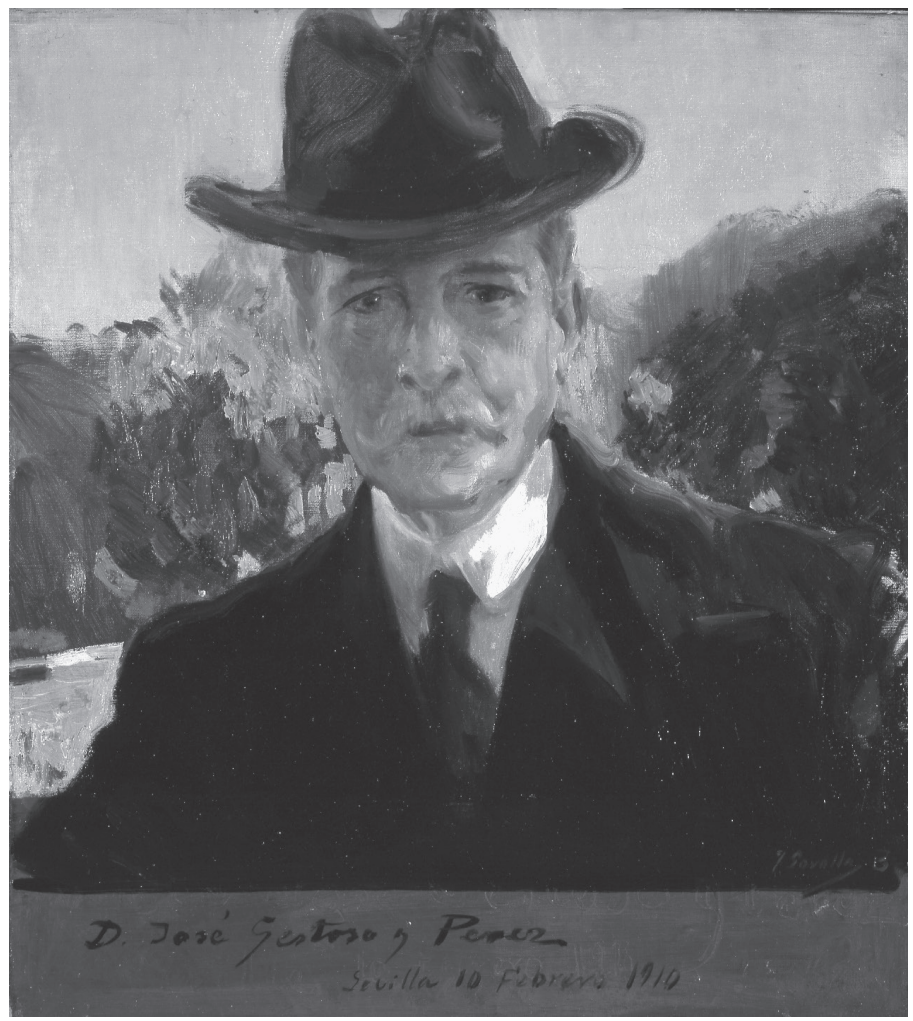

ros historiadores del arte en España ${ }^{6}$, de modo que siguiendo su criterio hemos estudiado al personaje teniendo en cuenta dos factores: por un lado el ambiente en el que se formó y por otro su personalidad. Estos aspectos nos servirán para valorar adecuadamente sus escritos dentro de la historiografía artística española y así comprender en qué circunstancias fueron elaborados y cómo influyó en ellos el contexto social y político en el que vivió su autor. Comprobaremos además cómo su carácter fue decisivo a la hora de dedicar grandes esfuerzos a favor de la protección del patrimonio histórico-artístico, como complemento y colofón a su actividad investigadora. A este respecto, resulta muy oportuna una acertada observación del investigador británico Nigel Glendinning sobre la práctica historiográfica donde nos recuerda que aunque esta exige objetividad, el autor no puede dejar a un lado su propio ser a la hora de interpretar la historia: "No se niega, desde luego, el valor de los datos fidedignos y los documentos, y lo cierto es que pueden publicarse a veces sin comentarios. Pero el cien-

VEGA, Jesusa, "La Historia del Arte y su devenir en España”, en La Historia del Arte en España. Devenir, discursos y propuestas, Polifemo, Madrid, 2016, p. 33. tífico que los analiza, por mucho rigor, método y conocimientos que ponga, también tiene sus querencias, sus prejuicios y obsesiones"7.

\section{Formación en la práctica historiográfica restauracionista}

José Gestoso y Pérez nació en Sevilla el 25 de mayo de 1852 en el seno de una familia de posición social acomodada. Después de unos años de juventud un tanto desordenados comenzó sus estudios en la Universidad Literaria de Sevilla, licenciándose en Derecho Civil y Canónico en el año 1881. Amante desde niño de la historia, la literatura y las antigüedades, no tardó en darse cuenta de lo alejados que quedaban sus intereses trabajando como jurista. Animado por su vecino y mentor, Juan José Bueno, director de la Biblioteca Provincial y Universitaria de Sevilla, se matriculó en la Escuela Superior de Diplomática de Madrid donde

\footnotetext{
GLENDINNING, Nigel, "Prólogo", en Cossio, Lafuente, Gaya Nuño. El descubrimiento del arte español: tres apasionados maestros, Novatores, Madrid, 2004, p. 7.
} 
obtuvo el título de Archivero, Bibliotecario y Anticuario $^{8}$.

Esta Escuela fue ideada y fundada en 1856 bajo la protección de la Real Academia de la Historia para formar a los profesionales que debían de encargarse de la custodia del ingente patrimonio que había pasado a formar parte del Estado tras los decretos desamortizadores y el consecuente traslado de los bienes de iglesias, conventos y monasterios a las colecciones públicas. A mediados del siglo XIX el aparato burocrático español no estaba preparado para ocuparse de la creciente masa de documentos, libros y obras de arte que habían pasado a formar parte del patrimonio de la nación. Para cubrir esta carencia surgió el cuerpo facultativo de Archiveros, Bibliotecarios y Anticuarios, en el que se ingresaba tras obtener la pertinente titulación en la Escuela Superior de Diplomática y una vez superados los ejercicios relativos a la oposición ${ }^{9}$. Pero aunque la intención de Gestoso fue la de ingresar en este cuerpo, finalmente obtuvo, también por oposición, la plaza de profesor de Teoría e Historia de las Bellas Artes en la Escuela de Bellas Artes de Sevilla en noviembre de 1885. En este centro desarrolló una continua y larga labor docente hasta su muerte en 1917, trabajo que simultaneó con la dedicación a los estudios de historia del arte y con su compromiso con la protección de la cultura nacional a través de distintas iniciativas $\mathrm{y}$ actividades.

La formación de José Gestoso en la Escuela Superior de Diplomática de Madrid fue esencial para su actividad investigadora y similar a la del resto de estudiosos de la historia y del arte en España durante la Restauración borbónica. El análisis de sus trabajos revela que estuvo en plena sintonía en cuando a objeto y método de estudio con la producción historiográfica académica de finales del siglo XIX de modo que es necesario conocer este contexto tan determinado para comprender sus obras, pues hasta comienzos del siglo XX no hubo historiadores profesionales en España, por tanto en tiempos

\footnotetext{
$8 \quad$ Para conocer en mayor profundizar la biografía de José Gestoso, véase CASQUETE DE PRADO Y SAGRERA, Nuria, José Gestoso..., opus cit.

9 Sobre la Escuela Superior de Diplomática véase el estudio de: PASAMAR ALZURIA, Gonzalo y PEIRÓ MARTÍN, Ignacio, La Escuela Superior de Diplomática. Los archiveros en la historiografía española contemporánea, ANABAD, Madrid, 1996.
}

de José Gestoso la práctica historiográfica estuvo en manos de la erudición académica ${ }^{10}$.

El escaso rendimiento social y cultural de los estudios históricos en la universidad española durante el siglo XIX había motivado que el desarrollo y perfeccionamiento de estos quedaran en manos de la Real Academia de la Historia y por extensión en la Escuela Superior de Diplomática; de sus aulas surgieron los eruditos académicos, es decir, los nuevos estudiosos de la historia nacional, adecuadamente formados y preparados para ocuparse de la protección del patrimonio archivístico, bibliográfico e histórico-artístico de la nación. Estos eruditos se dedicaron a la investigación histórica apoyados en los llamados "saberes de anticuario", actualmente conocidos como ciencias auxiliares de la Historia, es decir, $\mathrm{Pa}-$ leografía, Numismática, Heráldica o lenguas como el latín ${ }^{11}$. El conocimiento de la documentación histórica y la adquisición de las destrezas necesarias para su investigación se convirtió en uno de los puntales de la formación de los eruditos académicos. En la Escuela se les recalcó que toda crítica histórica debía fundamentarse en hechos comprobables, para de esta forma no incurrir en errores difundidos a través de la transmisión de tradiciones y leyendas, y por tanto su calidad se medía en tanto se pudiera contrastar documentalmente la información suministrada. De esta manera a los alumnos de la Escuela Superior de Diplomática se les inculcó que la base de sus trabajos de investigación debían apoyarse en las fuentes históricas primarias, especialmente las documentales, y en su posterior análisis y crítica $^{12}$.

En línea con estos "saberes de anticuario" también debe incluirse el estudio de monumentos y antigüedades en la Escuela, donde destacó uno de sus más prestigiosos profesores, Juan Facundo Riaño, de cuya asignatura, Arqueología y Bellas Artes, fue alumno Gestoso. El con-

\footnotetext{
10 Esta es el argumento defendido y bien argumentado por PEIRÓ MARTÍN, Ignacio, Los guardianes de la Historia. La historiografía académica de la Restauración, Institución Fernando el Católico, Zaragoza, 2006.

11 PEIRÓ MARTÍN, Ignacio: Los guardianes..., opus. cit., pp. 34-35.

12 Esta tendencia historiográfica también se desarrolló por el resto de Europa, véase PASAMAR ALZURIA, Gonzalo y PEIRÓ MARTÍN, Ignacio: La Escuela..., opus. cit., pp. 17-19; BERGER, Stefan, "The role of national archives in constructing national master narratives in Europe", Archival Science, 13, Luxemburgo, 2013, pp. 1-22.
} 
tacto de Riaño con la cultura anglosajona, a la que había accedido gracias a su suegro, Pascual de Gayangos, le permitió conocer la evolución de la historiografía artística europea, convirtiéndose en el introductor en España de un enfoque del estudio de los objetos artísticos en el que se ponderaba tanto la antigüedad como sus caracteres estéticos ${ }^{13}$. Es por esa razón que debemos subrayar la figura de Riaño y valorar su papel como introductor de la historia del arte como asignatura específica en la docencia española, diferenciada de los enfoques de carácter literario y arqueológico ${ }^{14}$.

A pesar de la corta trayectoria de la Escuela Superior de Diplomática -fue suprimida en 1900 dentro del plan de reestructuración del Ministerio de Instrucción Pública y Bellas Artes-, ejerció un papel fundamental en la gestación de la disciplina histórica en España. Sin la fundación de la Escuela, no podría haber sido posible en este momento la conversión de los infravalorados "saberes de anticuario" en la historiografía oficial española, de modo que, en consecuencia, fue una institución clave en su profesionalización ${ }^{15}$. Basta rastrear las páginas de las revistas de temática histórica, artística y arqueológica más importantes del país a finales del siglo XIX, a saber: Museo Español de Antigüedades, Boletín de la Real Academia de la Historia, Bole-

13 PASAMAR ALZURIA, Gonzalo, "De la Historia de las Bellas Artes a la Historia del Arte”, Historiografía del arte español en los siglos XIX y XX, Centro de Estudios Históricos, Madrid, 1995, p. 140; PASAMAR ALZURIA, Gonzalo y PEIRÓ MARTÍN, Ignacio, La Escuela..., opus. cit., p. 7.

14 BORRÁS Y GUALÍS, Gonzalo M., Cómo y qué investigar en historia del arte: una critica parcial de la historiografía del arte española, Ediciones del Serbal, Barcelona, 2001, p. 28; acerca de la indefinición disciplinar entre los estudios histórico-artísticos y arqueológicos, véase DÍAZ-ANDREU GARCÍA, Margarita, "Arte y arqueología. La larga historia de una separación”, en Historiografía del arte, opus. cit., pp. 151-160 y PASAMAR ALZURIA, Gonzalo, "De la Historia...", opus. cit., pp. 137-149. No obstante, hubo otras más instituciones en las que se impartieron y desarrollaron los estudios sobre historia de las bellas artes como la Institución Libre de Enseñanza, cf. CABALLERO CARRILLO, Rosario, Inicios de la historia del arte en España: la Institución Libre de Enseñanza (1876-1936), Consejo Superior de Investigaciones Científicas, Madrid, 2002; otras instituciones aparecen recogidas por MARTÍN MARTÍNEZ, José, "Genealogía de la Historia del Arte en tiempos de Elías Tormo", en Elías Tormo, apóstol de la Historia del Arte en España, Institució Alfons el Magnànim, Valencia, 2016, pp. 69-78.

15 PASAMAR ALZURIA, Gonzalo y PEIRÓ MARTÍN, Ignacio, La Escuela..., opus. cit., p. 123. tín de la Sociedad Española de Excursiones ${ }^{16}$ o Revista de Archivos, Bibliotecas y Museos, para comprobar que en todas ellas colaboraron y publicaron artículos los profesores y alumnos de la Escuela Superior de Diplomática, entre los que destacamos los que escribieron sobre temática histórico-artística como Juan Facundo Riaño, Juan Catalina García, Rodrigo Amador de los Ríos, José Ramón Mélida, Narciso Sentenach y por supuesto José Gestoso.

En conclusión, durante la Restauración borbónica y hasta principios del siglo XX, la historiografía estuvo controlada por los miembros de la Real Academia de la Historia y los profesores y alumnos de la Escuela Superior de Diplomática, cuyo método de estudio se fundamentó en el empleo riguroso de la documentación histórica ${ }^{17}$.

\section{Sobre la producción historiográfica de José Gestoso}

De toda la producción escrita de temática histórico-artística de José Gestoso hemos extraído una serie de notas que caracterizaron su quehacer historiográfico y que a la vez conformaron su método de investigación ${ }^{18}$. Aunque este estuvo predeterminado por un marcado positivismo, otras corrientes de pensamiento así como sus propios intereses y aficiones fueron definiendo una manera particular de escribir sobre historia y arte.

José Gestoso estudió en la Escuela Superior de Diplomática y su método de trabajo, fundamentado en la construcción de la historia nacional en base al estudio de las fuentes reco-

\footnotetext{
16 Sobre la importancia de esta publicación y de la Sociedad, véase BODELÓN RAMOS, Terencio Borja, Enrique Serrano Fatigati y la Sociedad Española de Excursiones, Tesis Doctoral inédita defendida en la Universidad Nacional de Educación a Distancia en 2015.

17 Como ya ha señalado Ignacio Peiró, esta misma tendencia historiográfica se extiende a la totalidad de escritores que siguieron las directrices y modas impuestas, desde catedráticos de universidad hasta eruditos locales, cf. PEIRÓ MARTÍN, Ignacio, Los guardianes..., opus. cit., p. 90 y 36).

18 José Gestoso fue un autor muy prolífico que publicó cuarenta monografías y más de cien artículos en revistas especializadas; un listado en CASQUETE DE PRADO SAGRERA, Nuria, José Gestoso..., opus. cit., pp. 383-404. Sus monografías, acompañadas de una breve reseña, pueden consultarse en el portal de Exposiciones Virtuales de la Biblioteca de la Universidad de Sevilla: http://expobus.us.es/omeka/exhibits/show/jose-gestoso).
} 
gidas en los archivos del país, es como hemos señalado, deudor de los postulados emanados de la Real Academia de la Historia durante la segunda mitad del siglo XIX. El empleo de la documentación histórica es la base sobre la que apoyan sus investigaciones, ya que trataba de evitar incurrir en errores derivados del seguimiento de antiguas tradiciones, por eso sustentó todos sus trabajos en el estudio documental. La recogida de datos y la recopilación de fuentes, preferentemente fuentes primarias, conformaron la base del método de investigación durante la época restauracionista y así lo reconocía el propio Gestoso: "[sobre] la infınita documentación publica y privada que hace tiempo venimos examinando, fuentes de irrefragable autenticidad, exentas de apasionamientos, en las cuales aparecen los hechos tales como acaecieron y los hombres bajo su verdadero aspecto; ruin y miserable ú honrado y nobilísimo" 19 .

Prueba de la seguridad de Gestoso en el empleo de los documentos como base para su método de trabajo, son las impresiones que comparte con el lector de una de sus obras más importantes, Sevilla Monumental y Artística:

Hasta ahora, que sepamos, ningún escritor ha llegado a examinar los legajos de Archivo, siendo muy extraño este hecho en los antiguos, puesto que tratando de los demás monumentos sevillanos acudieron infatigables a la documentación relacionada con su historia, $y$ en cuando a los modernos, más exigentes, desentendiéndose de aventurados juicios $y$ de atrevidas hipótesis, buscan la verdad de los hechos en los únicos comprobantes admitidos hoy, en los documentos y papeles coetáneos o de irrefragable autoridad ${ }^{20}$.

Pero al margen del contexto académico en el que se formó, Gestoso estuvo interesado en el estudio de la historia y del arte a través de

19 GESTOSO Y PÉREZ, José, Historia de los barros vidriados sevillanos: desde sus orígenes hasta nuestros dias, Tipografía La Andalucía Moderna, Sevilla, p. 331.

20 GESTOSO Y PÉREZ, José, Sevilla Monumental y Artística: historia y descripción de todos los edificios notables, religiosos y civiles que existen actualmente en esta ciudad y noticia de las preciosidades artísticas $y$ arqueológicas que alli se conservan, Oficina tipográfica de El Conservador, Sevilla, 1889, vol. I, p. 297. la información suministrada por la documentación de archivo desde muy joven ${ }^{21}$. Más que un trabajo, sus investigaciones documentales eran su principal afición y así se lo hizo saber en varias ocasiones a amigos como el historiador del arte Manuel Gómez-Moreno Martínez: "No tengo más Dios y Sta. María que registrar papeles y papeles. Con nadie cumplo, mis amigos todos se me quejan y yo acometido ya del vértigo de la investigación á ella dedico todo mi tiempo en absoluto"22.

El interés de José Gestoso por la búsqueda de la información de archivo le llevó a dar a conocer y a difundir las noticias documentales histórico-artísticas que iba encontrando durante sus jornadas de investigación en los archivos sevillanos. De todos ellos, uno de los más apreciados por él fue el de Protocolos Notariales, que solía visitar diariamente junto a su amigo, el literato Francisco Rodríguez Marín, a finales del siglo XIX. En esa época había pocos conocedores en España de la riqueza de esta documentación notarial, entre ellos José Martí y Monsó ${ }^{23}$, y hubo que esperar a las investigaciones de Elías Tormo en el Centro de Investigaciones Históricas y el proyecto del Fichero de Artistas para que se extendiera entre los investigadores del arte español ${ }^{24}$.

21 En el protocolo n 477 del Archivo de Protocolos Notariales de Sevilla se encontró la siguiente inscripción: «Lo hizo José Gestoso en Sevilla el 7 de agosto de 1868 a los 16 años" y fue recogida por PALOMERO PÁRAMO, Jesús, “iSegún en papeles viejos se ha podido al fin saber!: Los fondos notariales y la Historia del Arte en Sevilla", en 1987-2007. 20 años con el Archivo Histórico Provincial de Sevilla, Junta de Andalucía, Consejería de Cultura, Sevilla, 2008, p. 43.

22 Archivo del Instituto Gómez-Moreno, Correspondencia 5710- $\mathrm{r}^{0}$ - 5711- $\mathrm{V}^{0}$, carta de José Gestoso a Manuel Gómez-Moreno Martínez, fechada el 25/06/1900.

23 BRASAS EGIDO, Carlos, "Apuntes sobre la vida y la obra de José Martí y Monsó (1840-1912)” en Boletín de la Sociedad Castellana de Excursiones (1905-1905), ed. facsimilar, tomo II, Grupo Pinciano, Valladolid, 1983, s/p. Agradezco al autor de la publicación y al profesor Enrique Valdivieso que me facilitaran una copia de la misma.

24 Sobre la labor de Elías Tormo en el Centro de Investigaciones Históricas y el proyecto del Fichero de Artistas véase: CABAÑAS BRAVO, Miguel, "La Historia del Arte en el Centro de Estudios Históricos de la JAE", en Tiempos de Investigación: JAE-CSIC, cien años de ciencia en España, Consejo Superior de Investigaciones Científicas, Madrid, 2007, pp. 144-146 y ARCINIEGA GARCÍA, Luis, "El Centro de Estudios Históricos, colmena de investigadores”, Elias Tormo..., opus. cit., pp. 107-112. 
José Gestoso dio a conocer la relevancia de este rico e ignoto patrimonio documental a través de la publicación de monografías y artículos de investigación que había desarrollado gracias a las noticias allí encontradas, pero la mejor propaganda que hizo de los Archivos de Protocolos Notariales y de su importancia para la historia del arte español fue a partir de la clausura del archivo de Sevilla en $1907^{25}$. El cierre del mismo afectó negativamente a Gestoso, tanto por haber perdido una fuente esencial para sus investigaciones como anímicamente. Por esta razón emprendió una iniciativa para dar a conocer su propuesta de crear archivos históricos en cada provincia y que estos custodiaran los fondos antiguos de los Archivos de Protocolos Notariales, para conservarlos y ponerlos a disposición de los estudiosos ${ }^{26}$. Entre las distintas acciones que promovió se encuentran los contactos con el senador Luis Palomo, quien defendió este proyecto en el Senado en 1909 con poco éxito; pidió apoyo a investigadores de otras provincias, entre ellos, Enrique Romero de Torres, Manuel Rodríguez Codolá, Luis Tramoyeres Blasco y Manuel Gómez- Moreno Martínez; solicitó el respaldo de la Real Academia de la Historia en 1911 y se manifestó públicamente mediante una comunicación en el Congreso de Historia y Geografía Hispanoamericana celebrado en Sevilla en 1914: "Un tesoro documental histórico casi desconocido".

Todos estos esfuerzos fueron aparentemente en balde pues Gestoso murió en 1917 sin haber obtenido ningún resultado de los mismos, pero como ha indicado Nuria Casquete de Prado, nuestro personaje fue uno de los impulsores de la creación de los Archivos Históricos Provinciales por decreto de 12 de noviembre de 1931, en cuyo texto se expone el mismo deseo

25 Esta clausura estuvo motivada por el nuevo responsable del archivo del colegio notarial, Antonio Lemus Malo de Molina; el profesor Jesús Palomero ha relacionado este cierre con los elevados costes de apertura al público del archivo, cf. PALOMERO PÁRAMO, Jesús, "El Archivo de Protocolos Notariales y la Historia del Arte en Sevilla" en Noticias de Arquitectura (17001720), Guadalquivir, Sevilla, 1990, pp. 11-16.

26 Este proyecto impulsado por Gestoso y todas las iniciativas con las que trató de sacarlo adelante fueron narradas por él mismo en un manuscrito donde recoge algunas memorias: Biblioteca Capitular y Colombina, Fondo Gestoso (en adelante BCC, FG), De Historia Sevillana. Páginas de mi vida, vol. I, fol. 352-375; este episodio ha sido recogido y dado a conocer por CASQUETE DE PRADO SAGRERA, Nuria, José Gestoso..., opus. cit, pp. 287-296. de Gestoso de establecer los archivos históricos provinciales y que estos estuvieran constituidos por los fondos procedentes de los de Protocolos Notariales de más de cien años ${ }^{27}$. De modo que la defensa que hizo nuestro protagonista de la consulta de estos archivos ayudó a tomar conciencia acerca de la importancia documental de estos repositorios. Él fue uno de los pioneros en el empleo y valoración de estas fuentes y el primero en defender el derecho de los investigadores a poder consultarlas. Con esta aportación ayudó a sentar las bases de la Historia del Arte en España, aportando rigor y veracidad, de modo que su influjo debe valorarse como una de las bases del método de trabajo de los historiadores del arte españoles, eminentemente de índole positivista, basado en la búsqueda de información en archivos ${ }^{28}$.

El positivismo es el rasgo que mejor caracteriza la práctica historiográfica de José Gestoso pero también recibió influencia de metodologías coetáneas para el estudio de los objetos artísticos, como el formalismo. En este sentido fue fundamental el desarrollo de la ciencia arqueológica y de sus métodos de trabajo, especialmente los estudios taxonómicos practicados en los museos durante el siglo XIX, que tan útiles resultaron para identificar, inventariar y catalogar el patrimonio histórico-artístico perteneciente a cada nación ${ }^{29}$. En España este trabajo de catalogación estuvo en manos del cuerpo de Archiveros, Bibliotecarios y Anticuarios, cuyos miembros ya habían sido previamente formados en este tipo de tareas en la Escuela Superior de Diplomática.

En este centro José Gestoso también aprendió a aplicar el método formalista, circunstancia que le permitió despegarse de los documentos para centrarse en la obra de arte como primera fuente para el estudio de la historia de arte. Aunque como él mismo reconoció, esto sólo ocurría cuando no tenía documentación de archivo que poder consultar y confrontar, concretamente, en el estudio de la cerámica sevillana: "Falto pues de antecedentes escritos, he tenido que interrogar á los monumentos y obje-

27 CASQUETE DE PRADO SAGRERA, Nuria, José Gestoso..., opus. cit, pp. 294-296.

28 Así ha sido puesto de manifiesto por Borrás Gualís, Gonzalo M., “A modo de introducción”, en Diccionario de historiadores españoles del arte, Cátedra, Madrid, 2006, p. 13.

29 HERNÁNDEZ HERNÁNDEZ, Francisca, Los museos arqueológicos y su museografía, Gijón, Trea, p. 26. 
tos mismos, acudiendo á la olvidada documentación de nuestros archivos; no satisfecho aun, vistiendo la blusa del obrero, he practicado en los alfares trianeros" 30 .

Pero al margen de esas incursiones experimentales su obra de investigación más conocida y valorada es un valioso compendio documental: Sevilla Monumental y Artística (1889-1892), un completo estudio histórico-artístico en tres volúmenes sobre los monumentos sevillanos donde el autor demuestra su habilidad para la investigación de archivo. La obra fue encargada a Gestoso mediante acuerdo establecido con el Ayuntamiento de Sevilla el 3 de febrero de 1883 y su publicación supuso toda una novedad en el panorama historiográfico español de la época, pues nadie había tenido la audacia de emprender un proyecto de tal magnitud, en el que se presentara información rigurosa y precisa sobre el patrimonio monumental de una ciudad.

La estructura de Sevilla Monumental y Artística es sencilla; sus tres volúmenes recogen cronológicamente y siguiendo el clásico esquema evolutivo los monumentos más importantes de la ciudad, abarcando desde los recién descubiertos dólmenes de Valencina de la Concepción de los "tiempos prehistóricos" hasta las edificios barrocos "de mal gusto". A lo largo de sus páginas se aprecia a la perfección que la base del método historiográfico de José Gestoso se apoya en lo que él llama "crítica histórico artística”, es decir, la investigación de la historia del arte fundamentada en documentación de archivo, documentación que extractada y transcrita incluye en las páginas de sus obras, con el fin de que el lector pueda comprobar de primera mano que nada hay inventado ni recogido de la tradición oral en los estudios del autor, sino que estos cuentan con un el soporte de las fuentes históricas, rasgo que como hemos visto fue la base de la práctica historiográfica académica de finales del siglo XIX. Se puede constatar con facilidad en las referencias que aporta su continuada consulta a los principales archivos de Sevilla: el Municipal, el de Catedral, el del Arzobispado, el de conventos femeninos y el de Protocolos Notariales.

Aunque el esfuerzo que se tomó Gestoso por ofrecer información rigurosa sobre los monumentos sevillanos es loable, la constante inclu-

\footnotetext{
30 GESTOSO Y PÉREZ, José, Historia de los barros..., opus. cit., s/p.
}

sión de largas transcripciones a lo largo de esta y de la mayor parte de sus publicaciones entorpece el ritmo narrativo de las mismas. Pero al margen de su afán documentalista podemos encontrar tanto en Sevilla Monumental y Artística como en el resto de su producción escrita descripciones muy precisas de los monumentos que estudia, en las que emplea un lenguaje técnico y especializado.

Otra obra de José Gestoso que ha tenido buena fortuna historiográfica ha sido su Ensayo de un Diccionario de Artifices que florecieron en esta ciudad de Sevilla desde el siglo XIII hasta el XVIII, publicado en tres tomos entre 1899 y 1909 y en la que demuestra su interés en el estudio de los artistas y artesanos. Los tres volúmenes están dedicados íntegramente a recoger datos documentales que para el autor son elementos incuestionables que aportan el rigor que necesitan los estudios histórico-artísticos. Su conocida afición por el acopio de datos documentales resultó especialmente útil en este trabajo, que combina dos tendencias culturales de la época: por un lado la revalorización de las artes industriales, potenciada por el gobierno de Cánovas del Castillo y que Gestoso apoyó decididamente y por otro, y también fruto del pensamiento historiográfico restauracionista, el creciente interés por la historia de las clases sociales. La necesidad por atender ambas cuestiones es manifestado por el autor al comienzo del primer tomo de este diccionario: "La ignorancia de la historia artístico-industrial de España llega á un punto tal entre el común de las gentes, que ni aun se saben los nombres de muchos de los oficios que en los siglos medios florecían en las ciudades y pueblos de la Península" ${ }^{31}$.

Pero no todo es documentación de archivo en la producción de José Gestoso; entre las aportaciones más importante al estudio de la historia del arte en España se encuentran sus investigaciones sobre cerámica sevillana que desarrolló de manera simultánea junto a la revitalización de este arte desde los alfares trianeros. Aunque su obra historiográfica es más conocida y valorada por sus aportaciones documentales, en su estudio sobre los barros vidriados sevillanos Gestoso supo combinar con acierto los métodos positivista y formalista. En

\footnotetext{
GESTOSO Y PÉREZ, José, Ensayo de un diccionario de los artífices que florecieron en Sevilla desde el siglo XIII al XVIII inclusive, La Andalucía Moderna, Sevilla, 1899, vol. I, p. XVIII.
} 
este ámbito hubo de ser muy inspirador el magisterio de Juan Facundo Riaño, precursor de los estudios de artes industriales y decorativas en España y de su revalorización ${ }^{32}$. Los estudios sobre cerámica artística comenzaron a desarrollarse en Europa a mediados del siglo XIX pero la cerámica española había recibido poca atención al margen de los estudios de Riaño, que fueron seguidos por Pablo Alzola con El arte industrial en España (1892). Pero el arte de la cerámica en Sevilla era a finales del siglo XIX un campo de investigación del todo desconocido y no sencillo de estudiar y sistematizar, circunstancia que no supuso impedimento alguno para que Gestoso llevara a cabo una de sus obras de mejor fortuna historiográfica: Historia de la barros vidriados sevillanos (1903) y que le convirtió en el primer investigador metódico de la cerámica sevillana ${ }^{33}$.

3. Conocer para conservar: el reflejo de la actividad historiográfica de José Gestoso en la protección del patrimonio históricoartístico

A lo largo de la producción historiográfica de José Gestoso puede comprobarse no sólo la extraordinaria cantidad de información documental inédita que extractó de diversos archivos, sino que además estuvo muy implicado en la protección del patrimonio histórico-artístico español ${ }^{34}$. Para él los monumentos eran, igual que los documentos, testigos de la historia y como tales merecían ser conservados. Este hecho, al igual que el sentimiento de preocupación ante la falta de protección del patrimonio monumental, se aprecia desde los primeros artículos y monografías que publicó durante los últimos años de la década de 1870 y posteriormente a lo largo de su vida. En este sentido resulta fundamental reconocer la valentía de este

32 En este área es conocido fundamentalmente por su obra The Industrial Arts in Spain, Chapman and Hall, Londres, 1879.

33 Sobre José Gestoso y sus estudios y contribuciones a la revitalización de la cerámica sevillana, véanse las investigaciones del profesor Pleguezuelo: PLEGUEZUELO HERNÁNDEZ, ALFONSO, "Presentación”, opus. cit.; “José Gestoso y la recuperación...”, opus. cit.; “José Gestoso (1852-1917) y la cerámica de Triana”, Boletín de Bellas Artes, 2a época, $n^{\circ}$ XLIV, Sevilla, 2016, pp. 71-91.

34 Véase el estudio de RUIZ DE LACANAL RUIZ-MATEOS, María-Dolores, “José Gestoso...”, opus. cit. autor al no dudar nunca en denunciar públicamente todos los abusos que se cometían contra el patrimonio histórico-artístico, ya se tratara de la destrucción, robo o mal uso del mismo.

Gestoso llevó a cabo su labor de protección del patrimonio como miembro de instituciones como la Comisión Provincial de Monumentos, de la que llegó a ser vicepresidente ${ }^{35}$, de las academias sevillanas de Buenas Letras y Bellas Artes y como académico correspondiente de la Real Academia de la Historia y de Bellas Artes de San Fernando. En todas estas instituciones contó con amigos, colegas y en suma, contactos de importancia del ambiente cultural restauracionista. Su empeño personal fue fundamental para la consecución de sus iniciativas en este y en otros ámbitos pero es indudable que sus excelentes relaciones sociales determinaron en muchas ocasiones el éxito de las mismas, tal y como el mismo protagonista recordaba:

Algo he conseguido, unas veces solo, otras con la cooperación de las corporaciones de que he formado parte; porque tratándose en la mayoría de los casos, de asuntos relacionados con el Estado, no hubiese sido bastante la accion individual, pues por su indole era necesario atenerse a trámites oficiales, pero, ya de una manera ya de otra, he tenido algunas veces la intima complacencia de ver satisfechas mis aspiraciones y logrados mis propósitos ${ }^{36}$.

Gracias a sus desvelos se salvaron cuantiosas obras de arte y monumentos tan destacados como la iglesia de la primitiva Universidad de Sevilla y la capilla de San José de dicha ciudad. Por tanto, como complemento a la producción historiográfica de José Gestoso, debe unirse su activismo como defensor del patrimonio histórico-artístico, que él concibe como testimonio del pasado y evocador del mismo. Así lo dejó escrito Gestoso al final de su vida, al explicar con claridad cuáles fueron las razones que le llevaron a dedicarse por completo al estudio y a la protección del patrimonio histórico-artístico sevillano:

35 Sobre la actividad de José Gestoso en la Comisión Provincial de Monumentos de Sevilla véase LÓPEZ RODRÍGUEZ, Raquel M., La Comisión de Monumentos Históricos y Artísticos de la Provincia de Sevilla, Diputación Provincial, Sevilla, 2011.

36 BCC, FG, De Historia Sevillana..., opus. cit., s/n. 
Velar por la conservacion de tantos inmortales recuerdos, defendiéndolos de los ataques de la ignorancia, de la funesta acción del egoismo y de los tristes resultados de la apatia y de la indiferencia, procurando siempre que mi Sevilla conserve los prestigios y alto renombre que la historia le reconoce; tales han sido los poderosos móviles de la labor de toda mi vida, el fin que he perseguido, y a los que he dedicado mis facultades todas ${ }^{37}$.

De nuevo debemos relacionar este interés con Juan Facundo Riaño y con una iniciativa muy concreta como fue la elaboración del proyecto de redacción del Catálogo Monumental de España, auspiciado por él y materializado gracias al apoyo político del ministro de Fomento Alejandro Pidal ${ }^{38}$. Riaño sabía que esta labor de conocimiento previo era fundamental para poder desarrollar un adecuado trabajo de salvaguarda de los bienes culturales del país, de ahí su interés en iniciar cuanto antes esta empresa, sabedor de la constante amenaza de destrucción y expolio. Por Real Orden de 1 de junio de 1900 dieron comienzo los trabajos conducentes al inventario y clasificación de los bienes del patrimonio histórico-artístico español, si bien esta actividad tuvo resultados desiguales ${ }^{39}$.

La tutela del patrimonio histórico-artístico fue concebida por Gestoso como una sola acción pero fundamentada en cuatro aspectos esenciales: el estudio, la conservación, la restauración y la difusión. Esta concepción es muy similar a la que se sigue actualmente en la salvaguarda de los bienes culturales, pero era del todo inusual a finales del siglo XIX y a principios del XX y sólo entre los círculos académicos madrileños se había adquirido plenamente la noción de patrimonio histórico-artístico y los valores que le son consustanciales. Gracias a la pertenencia de Gestoso al ambiente de las Reales Academias, de las que era miembro corres-

37 Ídem.

38 LÓPEZ-OCÓN CABRERA, Leoncio, "El papel de Juan Facundo Riaño como inductor del proyecto cultural del Catálogo Monumental de España”, en El catálogo monumental de España (1900-1961). Investigación, restauración y difusión, Ministerio de Educación, Cultura y Deporte, Madrid, 2012, pp. 49-74.

39 LÓPEZ-YARTO ELIZALDE, Amelia (coord.), El catálogo monumental..., opus. cit.; actualmente se puede consultar en línea en http://biblioteca.cchs.csic.es/digitalización_tnt/ [Consulta: 30/04/2018]). pondiente, su formación en Madrid y a buena parte de sus amigos, que también desarrollaban su actividad profesional en este ambiente, pudo conocer y llevar a la práctica en la región las acciones encaminadas a la preservación de su patrimonio monumental y artístico ${ }^{40}$.

\section{Conclusiones}

Del estudio y análisis de la obra historiográfica de José Gestoso podemos inducir que como escritor e investigador de temas histórico-artísticos fue un hombre de su época; no nos encontramos ante un personaje excepcional en este sentido, sino frente a un claro exponente de la cultura oficial restauracionista, pues sus investigaciones y su obra escrita en general, están plenamente integradas en este contexto, donde fue valorado y respetado.

Pero a pesar de que la labor historiográfica de José Gestoso no fue excepcional en esta época en España, pues otros personajes como José Martí y Monsó, Luis Tramoyeres o Vicente Lampérez elaboraron estudios histórico-artísticos similares, sí lo fue en Sevilla, ciudad en la que ya se habían llevado a cabo estudios sobre su rico patrimonio, pero que hasta la aparición de nuestro protagonista no habían alcanzado el carácter sistemático y riguroso que los suyos presentan. Esta circunstancia fue por un lado muy positiva para el conocimiento de la riqueza monumental de Sevilla, pero también para el desarrollo de los estudios histórico-artísticos en España, ya que gracias a sus trabajos Gestoso generó una importante producción y conocimiento sobre el patrimonio cultural y la consolidación de las investigaciones documentales como base para estas.

La característica más importante de la obra historiográfica de Gestoso es su afán documental. Este rasgo, que ha propiciado en él una merecida fama de consumado documentalista, es a la vez una de sus principales rémoras. El apego hacia los datos extraídos en los archivos para investigar la historia del arte provocó que no supiera trascender de lo empíricamente demostrable, aunque esta inclinación debe comprenderse dentro de su contexto, y teniendo en cuenta que esto era para Gestoso y sus coetáneos un punto a su favor

\footnotetext{
40 Así ha quedado demostrado en DE-TENA-RAMÍREZ, Carmen, Conocer para conservar..., opus. cit.
} 


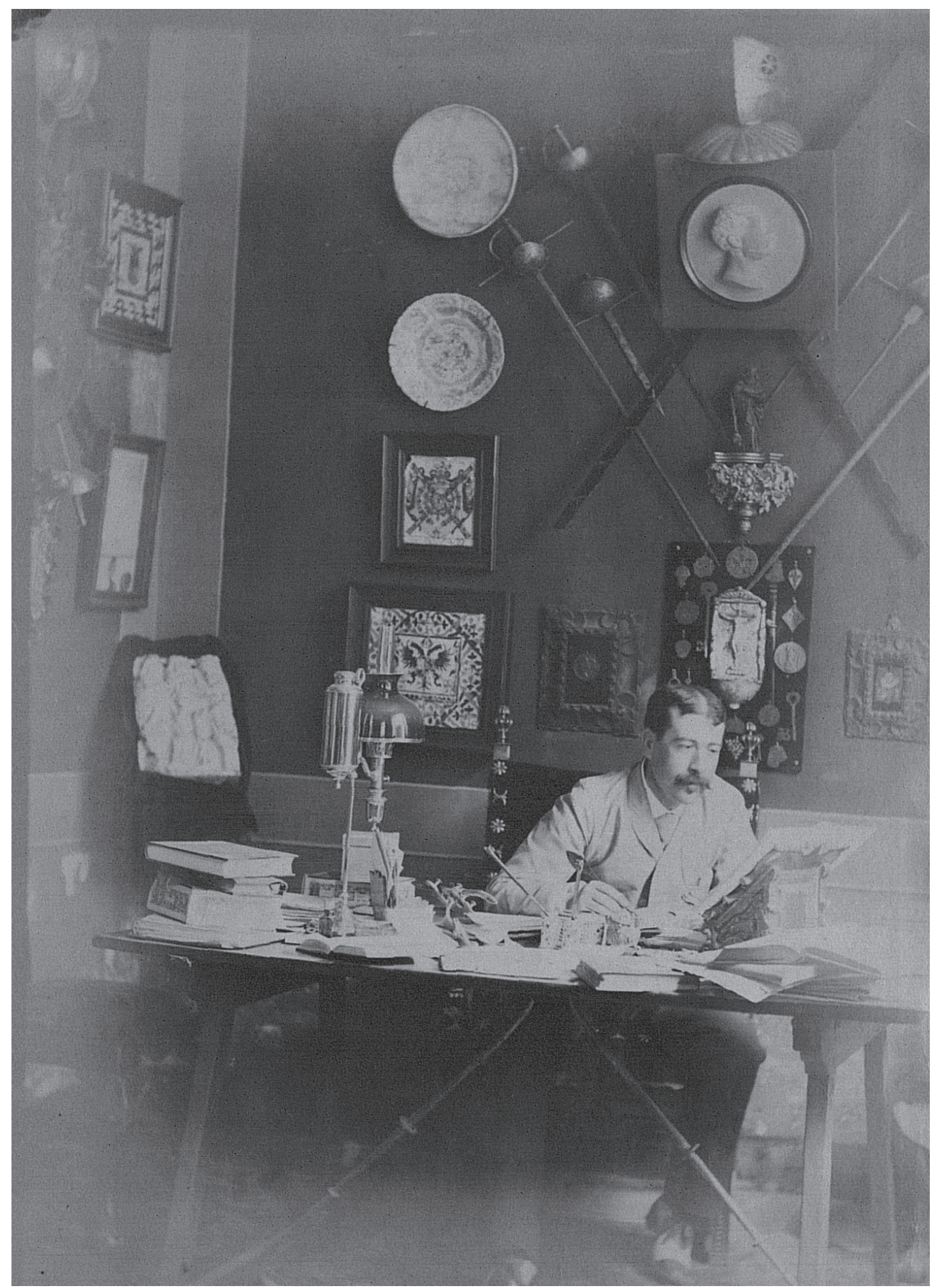

Figura 2. Fotografía de José Gestoso trabajando en su despacho, 1891. ${ }^{\circ B}$ Biblioteca Capitular y Colombina, Fondo Gestoso, Apuntes, vol. 9 , fol. 148 
que demostraba su rigor y profesionalidad. Pero sería injusto limitar los logros de Gestoso a sus aportes documentales, pues su prolífica obra historiográfica se complementa con las numerosas iniciativas de protección y salvaguarda de las artes y del patrimonio artístico. Por tanto, es la conjunción de conocimiento y protección el elemento que diferencia y caracteriza la actividad de Gestoso y por el que merece ser reconocido y recordado.

En conclusión, con este trabajo hemos querido dar a conocer la importancia de la labor historiográfica de José Gestoso, así como la posterior aplicación de los conocimientos históricos adquiridos para la conservación y la preservación del patrimonio artístico. El estudio de este personaje nos ha servido también para reflexionar acerca de los comienzos de la Historia del Arte en España y de su institucionalización, realidad que no fue posible hasta que el método de trabajo de esta especialidad quedó apoyado y establecido sobre una sencilla premisa: que la interpretación del objeto artístico debe hacerse desde una doble dimensión: la histórica y la estética. Este fue el gran logro de Elías Tormo, uno de los primeros historiadores del arte españoles y el primero en fundamentar la Historia del Arte sobre otras dos ciencias, la Historia y la Estética ${ }^{41}$. A José Gestoso le faltó tiempo y posiblemente también desapego del documento escrito para aprehender el método de trabajo propio de la Historia del Arte pero con él se cerró una página de la erudición histórico-artística en España, dando paso a la renovación de esta índole de estudios y a la adopción de los nuevos métodos de trabajo que cristalizarían en la conformación de nuestra disciplina y su institucionalización a comienzos del siglo XX.

${ }^{41}$ VEGA, Jesusa, “La Historia del Arte y...”, opus. cit. p. 37. 